\title{
Species- and community-level responses combine to drive phenology of lake phytoplankton
}

\author{
Annika W. Walters, ${ }^{1,4}$ María de los Ángeles González Sagrario, ${ }^{2}$ and Daniel E. Schindler ${ }^{3}$ \\ ${ }^{1}$ U.S. Geological Survey, Wyoming Cooperative Fish and Wildlife Research Unit, Department 3166, 1000 E. University Avenue, \\ University of Wyoming, Laramie, Wyoming 82071 USA \\ ${ }^{2}$ Instituto de Investigaciones Marinas y Costeras (IIMyC), CONICET-Universidad Nacional de Mar del Plata, Juan B. Justo 2550, \\ (7600) Mar del Plata, Argentina \\ ${ }^{3}$ School of Aquatic and Fishery Sciences, University of Washington, Box 355020, Seattle, Washington 98195 USA
}

Abstract. Global change is leading to shifts in the seasonal timing of growth and maturation for primary producers. Remote sensing is increasingly used to measure the timing of primary production in both aquatic and terrestrial ecosystems, but there is often a poor correlation between these results and direct observations of life-history responses of individual species. One explanation may be that, in addition to phenological shifts, global change is also causing shifts in community composition among species with different seasonal timing of growth and maturation. We quantified how shifts in species phenology and in community composition translated into phenological change in a diverse phytoplankton community from 1962 to 2000. During this time, the aggregate community spring-summer phytoplankton peak has shifted 63 days earlier. The mean taxon shift was only 3 days earlier, and shifts in taxa phenology explained only $40 \%$ of the observed community phenological shift. The remaining community shift was attributed to dominant early-season taxa increasing in abundance while a dominant late-season taxon decreased in abundance. In diverse producer communities experiencing multiple stressors, changes in species composition must be considered to fully understand and predict shifts in the seasonal timing of primary production.

Key words: climate change; Lake Washington; phenology; phytoplankton.

\section{INTRODUCTION}

Seasonality in temperate and polar ecosystems is marked by distinct growing seasons when primary producers accomplish the majority of their annual production and reproduction. A distinct lengthening of the growing season has been observed in a wide variety of ecosystems over the last few decades (Myneni et al. 1997), primarily associated with earlier green-up of primary producer communities (Parmesan 2006, Cleland et al. 2007). These phenological shifts are often linked to climate warming but other natural and anthropogenic stressors can also induce changes in phenology, including changes in nutrient loading and grazing regimes (Cleland et al. 2006, Gaedke et al. 2010). While shifts in the timing and duration of the growing season are an emergent community property derived from the aggregation of shifts in timing and dominance of individual species, surprisingly little attention has been given toward understanding how individual species responses scale up to the dynamics observed at the community level (Steltzer and Post 2009).

Manuscript received 7 March 2013; revised 19 June 2013; accepted 21 June 2013. Corresponding Editor: C. E. Cáceres.

${ }^{4}$ E-mail: annika.walters@uwyo.edu
Community- and species-level changes in phenology may not correspond for a variety of reasons. There could be dominant species that drive the community response (Meis et al. 2009) or compensatory dynamics that moderate the community shift (Vasseur and Gaedke 2007). There may even be divergent responses. For example, Steltzer and Post (2009) show that, even if individual plant species shorten their life-cycles, there could be a lengthening of the growing season at the community scale. Understanding the link between phenological shifts at the species and community level is useful for understanding and predicting ecosystemlevel effects.

One mechanism that is generally overlooked in studies of phenology is that there may be shifts in community composition that affect aggregate phenological responses. Community phenology could shift earlier, without a single species individually shifting its timing, if the relative abundance of early-season species increase relative to that of late-season species (Fig. 1). Many of the drivers of phenology also affect species composition (Post and Pedersen 2008, Guinder et al. 2010) making this a likely ubiquitous occurrence.

Here, we compare the contributions of shifts in species phenology and shifts in species relative abundance to phenological change at the community scale. We evaluate community and species phenology in a species-rich $(\sim 100$ phytoplankton taxa) aquatic eco- 
system over 40 years, during which the ecosystem showed distinct responses to changes in nutrient loading and climate forcing (Edmondson et al. 2003, Winder and Schindler 2004). Previous studies of phytoplankton phenology have focused on a few individual species (Thackeray et al. 2008) or on aggregate indicators of community biomass, such as chl $a$ (Kahru et al. 2011). By examining all taxa, we can compare the relative importance of phenological and compositional shifts to producer community response to environmental change.

\section{Methods}

We quantified changes in species and community phenology in the phytoplankton community of Lake Washington (Seattle, Washington, USA) from 1962 to 2000 (see Plate 1). Surface water samples were collected weekly to once every two weeks to bracket the period of thermal stratification (March-October) and monthly when the lake was entirely mixed (November-February) at a mid-lake sampling location, east of Madison Park (Edmondson et al. 2003). For each sample, at least 200 cells were counted with a subset measured to characterize the size range. Based on cell or colony measurements, algal biovolume was estimated using simple geometric analogs (Edmondson et al. 2003). Phytoplankton were identified to the lowest level possible, generally species. All samples were enumerated under the supervision of a single taxonomist (S. Abella) since 1974, and many earlier samples were re-enumerated by S. Abella to check for consistency.

We estimated the timing of the spring-summer bloom in each year for each individual phytoplankton taxon and total community phytoplankton biovolume for three community groupings: all taxa (104 taxa), all taxa except eutrophication-associated taxa (95 taxa), and continuously present taxa (37 taxa; Fig. 2). We removed the eutrophication-associated taxa to control for the effect of eutrophication in Lake Washington from 1941 to 1968. Eutrophication-associated taxa were primarily filamentous cyanobacteria and are those taxa that were only present or abundant early in the time series as described in Edmondson et al. (2003). The grouping with only continuously present taxa was our most conservative grouping; to be included a taxon had to be present in both the first and last five years of the time series (Appendix A: taxa list and community groupings).

We used phytoplankton samples from January through August to calculate the spring-summer bloom. We excluded September-December samples to remove the small fall bloom. An individual taxon had to be present in at least 10 years and 30 samples to be included in the analysis. We quantified the phenology of each phytoplankton taxon and the entire community in each year as the central tendency of the spring-summer phytoplankton peak (Edwards and Richardson 2004, Meis et al. 2009)
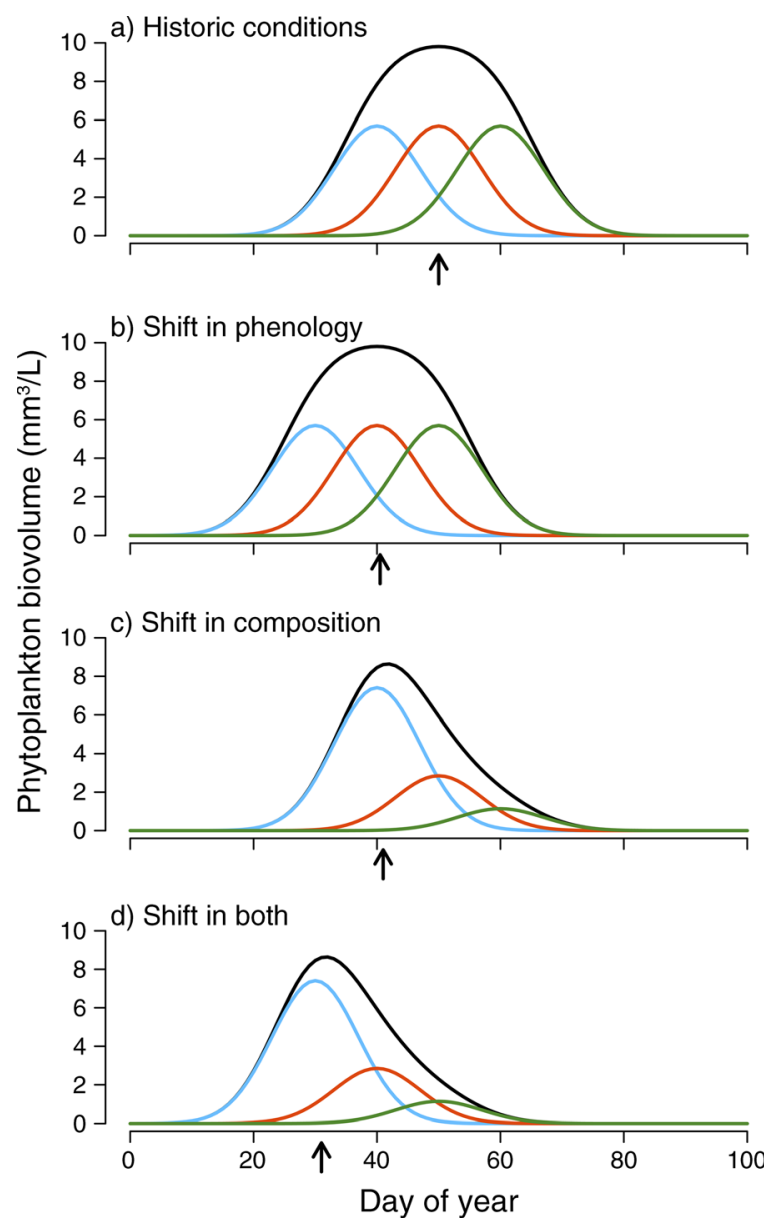

Fig. 1. (a) Bloom timing for a simulated phytoplankton community (black line; day of the peak bloom is marked with an arrow) and the three individual taxa (colored lines) comprising the community. (b-d) Distribution if (b) each individual taxon shifts 10 days earlier, (c) the early blooming taxa (blue) increase in abundance while the later blooming taxa (orange and green) decrease in abundance, and (d) the taxa both shift earlier and the early-blooming taxa increase in abundance.

$$
D=\frac{\sum_{i=1}^{244}\left(d_{i} \times m_{i}\right)}{\sum_{i=1}^{244} m_{i}}
$$

where $D$ is the day of year for the phytoplankton peak, $d_{i}$ is the $i$ th day of the year, and $m_{i}$ is the phytoplankton biovolume on the $i$ th day of the year. The average peak timing for a taxon is the mean of the yearly springsummer peak timings.

To examine phenological trends we fit a generalized additive model (GAM; Wood 2006) using R (R Development Core Team 2011) to the yearly day of peak phytoplankton biovolume for the community and individual phytoplankton. We conducted smoothing using penalized cubic regression splines with smoothing parameter estimation determined using generalized cross validation (Zuur et al. 2009). We calculated the shift in 


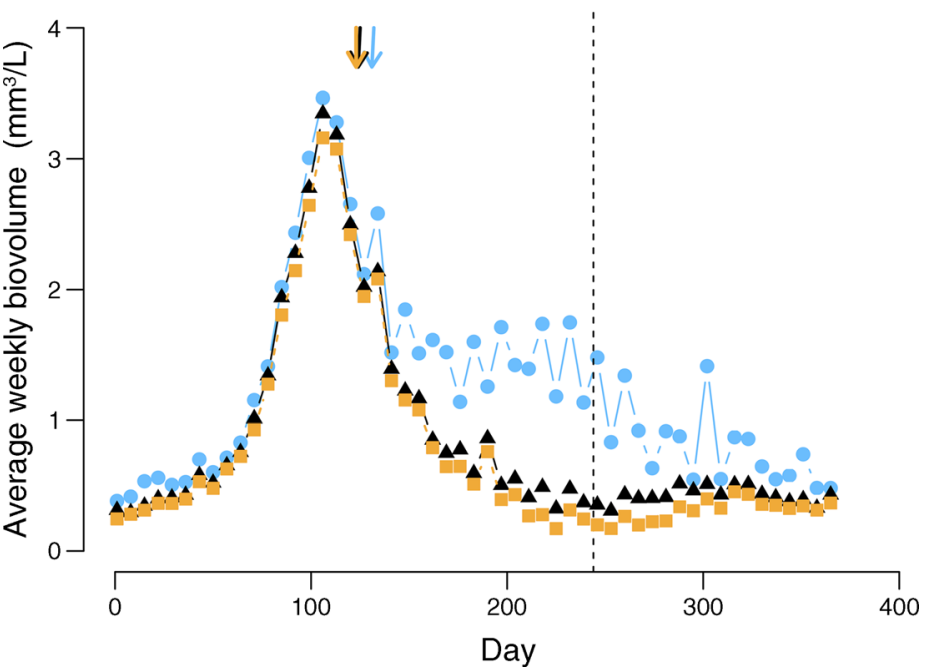

FIG. 2. Average total weekly phytoplankton biovolume $\left(\mathrm{mm}^{3} / \mathrm{L}\right)$ from 1962 to 2000 for all taxa (104, blue circles), all taxa except the eutrophication-associated taxa $(95$, black triangles), and only continuously present taxa (37, orange squares). The arrows mark average timing of peak phytoplankton biovolume (note the overlap of orange and black arrows). The dashed vertical line marks the cutoff day (1 September) for data inclusion in this analysis of the spring/ summer phytoplankton community. timing for a phytoplankton taxon, or the community, as the difference between the average model predicted timing for the last and first five years of data.

We calculated two summary metrics of the taxonspecific phenological shifts. The first was the mean of the taxon-level shifts. The second was the biovolumeweighted mean, which takes into account taxon dominance. The biovolume-weighted mean is the summation, over all taxa, of the phenological shift for a taxon multiplied by the average relative biovolume of that taxon (calculated as an average across all years). This metric can be viewed as an indicator of the extent of phenological shift in the community as determined only by changes in the phenology of individual taxa (i.e., independent of changes in community composition). The proportion of the biovolume-weighted mean to the overall shift was the percentage of the overall shift that was attributed to phenology. We attributed the remaining percentage to changes in community composition.

To quantify shifts in community composition, we calculated the relative biovolume of each taxon in each year. We fit a GAM model to the yearly relative biovolume data and calculated the shift in relative biovolume for each taxon over the time period as the difference between the average predicted relative biovolume for the last and first five years of data.

We examined three potential drivers of phenological shifts: nutrients, the seasonal timing of the onset of spring thermal stratification, and grazing. For nutrients we considered total phosphorus $(\mu \mathrm{g} / \mathrm{L})$ and used the average of all collected samples for each year; values were ln-transformed due to high values early in the time series. The onset of stratification was calculated using Schmidt's stability index with a threshold of 50 $\mathrm{g} \cdot \mathrm{cm} \cdot \mathrm{cm}^{-2}$ (see Winder and Schindler [2004] for an explanation). For grazing we considered the sum of Daphnia sp. and Diaptomus sp. abundance estimates for spring (March-June). We also examined Daphnia sp. and Diaptomus sp. separately (Appendix B). We related these potential drivers to community phenology for each community grouping and species phenology using multiple linear regression (Feuchtmayr et al. 2012). All model residuals were checked for independence, nonnormality, and heteroscedasticity by examining plots of residuals vs. time, residuals vs. fitted values, and quantile-quantile plots.

\section{RESUlts}

The spring-summer phytoplankton bloom shifted earlier by 63 days between 1962 and 2000, when considering all 104 taxa in the community, but that number was halved to 31 days if the nine eutrophicationassociated taxa were removed (Fig. 3a, d). In the most conservative scenario, with only the 37 continuously present species, the community peak abundance occurred 32 days earlier (Fig. 3g). Individual phytoplankton showed a wide variety of responses with $58 \%$ of taxa shifting earlier (Fig. 3b). The mean shift among all taxa was 3 days earlier, but at the extremes, peak abundance for one taxon shifted 107 days earlier and another shifted 126 days later (Fig. 3b). When the eutrophication-associated taxa were removed the mean shift was 4 days earlier, and for continually present taxa, the shift was 13 days earlier (Fig. 3e, h). If the average taxon shift was weighted based on its relative biovolume, the mean shift was approximately 20 to 25 days earlier for all community groups (Fig. 3b, e, h).

Shifts in the seasonal timing of individual taxa were inadequate for explaining the extent of the phenological shift observed at the aggregate community level. Even after taking into account taxa dominance, taxon shifts did not explain the community-level shift in phenology. Taxon phenological shifts explained $40 \%, 65 \%$, and $66 \%$ of the community-level shift for all taxa, all taxa except eutrophication-associated species, and continually present taxa, respectively. The remaining shift is likely due to shifts in community composition, specifically increased abundance of early-season phytoplankton taxa 

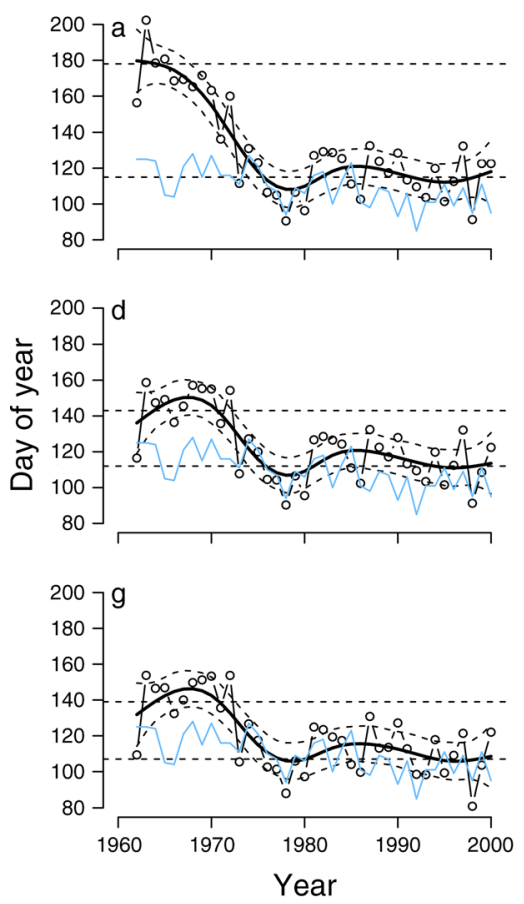

FIG. 3. (a, d, g) The day of peak total phytoplankton biovolume for each year and the generalized additive model (GAM) fitted to the data; the horizontal dashed lines mark the average predicted timing for the first and last five years, and the blue line marks the day of onset of stratification. (b, e, h) Histogram of shift in timing of peak biovolume for individual taxa with mean shift (dashed) and biovolume-weighted mean shift (solid) marked as vertical lines. (c, f, i) The shift in relative biovolume of individual phytoplankton taxa graphed against the average timing of the peak biovolume for that taxa. Taxa above the dotted line have become more dominant through time. The size of the bubble reflects the taxon's average relative abundance, and the color represents its functional group (green, diatoms; black, cyanobacteria; light blue, chlorophytes; red, cryptophytes; dark blue, dinoflagellates; orange, chrysophytes; and pink, other). The dashed lines correspond to the equivalent lines in panels (a), (d), and (g). Graphs represent all taxa (a, b, c, $n=104)$, all taxa except eutrophication-associated species $(\mathrm{d}, \mathrm{e}, \mathrm{f}, n=95)$, and only continuously present taxa (g, h, i, $n=37)$.

and decreased abundance of late-season phytoplankton taxa (Fig. 3c, f, i). For all taxa, the disappearance of the dominant late-season cyanobacteria species complex, Oscillatoria sp., contributed substantially to moving the community peak earlier (Fig. 3c). Once the eutrophication-associated taxa were removed, increases in the dominance of two abundant early-season diatoms, Aulacoseira subartica and Stephanodiscus niagarae accounted for the major compositional change (Fig. 3f, i).

Community phenology (all taxa) was related to total phosphorus levels, onset of stratification, and abundance of spring grazers (Table 1). With other variables held constant, day of peak phytoplankton biovolume was positively correlated with total phosphorus levels (1.6 days later with a $1 \mu \mathrm{g} / \mathrm{L}$ increase in total phosphorus) and day of onset of stratification (0.4 days later with a 1.0 day delay in the onset of stratification), and negatively correlated with abundance of grazers (1.0 day earlier with an increase in abundance of 10 grazers). The other two community groupings also showed a relationship with the drivers (Table 1), but the importance of the onset of stratification increased and the importance of nutrients decreased. For individual taxa, the phenology regressions generally had a modest fit $\left(R_{\text {adj }}^{2}<0.56\right)$, but 12 species showed a significant relationship with total phosphorus levels $(7$ species showed a positive relationship, 5 species showed a negative relationship), 11 with the onset of stratification (10 positive, 1 negative), and nine with the abundance of grazers (2 positive, 7 negative; Appendices $\mathrm{A}$ and $\mathrm{C}$ ).

\section{DisCUSSION}

The importance of scaling from individual species to the community level in phenology is recognized (Cleland et al. 2007). However, attempts in terrestrial systems to match green-up estimates based on remote sensing data to on-the-ground measurements have often led to poor correlations (Schwartz et al. 2002, Badeck et al. 2004, Fisher et al. 2007). Badeck et al. (2004) found that the correlation between satellite and ground phenology estimates was higher when taxa composition is known or homogenous, suggesting a compositional role. It is likely that, in many cases, mismatches result from not considering the importance of shifts in community composition, especially with respect to dominant taxa. This problem is illustrated clearly in the phytoplankton community of Lake Washington as we report here. 
TABLE 1. Results from multiple linear regressions relating nutrients, onset of stratification, and grazers to community phenology for each community grouping.

\begin{tabular}{|c|c|c|c|c|c|c|c|c|}
\hline \multirow[b]{2}{*}{ Community grouping } & \multicolumn{2}{|c|}{ Nutrients (ln TP) } & \multicolumn{2}{|c|}{ Onset of stratification } & \multicolumn{2}{|c|}{ Spring grazers } & \multicolumn{2}{|c|}{ Full model } \\
\hline & Coefficient & $P$ & Coefficient & $P$ & Coefficient & $P$ & $\overline{R_{\text {adj }}^{2}}$ & $P$ \\
\hline 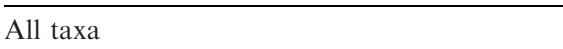 & 35.56 & $<0.001$ & 0.44 & 0.08 & -0.10 & 0.001 & 0.77 & $<0.001$ \\
\hline All taxa except eutrophication-associated taxa & 12.81 & 0.02 & 0.46 & 0.05 & -0.09 & 0.002 & 0.59 & $<0.001$ \\
\hline Continually present taxa & 12.82 & 0.02 & 0.50 & 0.03 & -0.09 & 0.003 & 0.59 & $<0.001$ \\
\hline
\end{tabular}

Note: TP is total phosphorus.

We found that taxon-specific changes in phenology were highly variable. The variation in phytoplankton taxa responses (and the drivers of these responses) is supported by other studies examining individual species (Adrian et al. 2006, Thackeray et al. 2008, Feuchtmayr et al. 2012). While some groups of taxa responded similarly, e.g., all three cryptophyte taxa shifted earlier, many groups, such as cyanobacteria, did not demonstrate consistent patterns emphasizing that it is important to examine species-level responses (Appendix A). While taxon-level phenological responses varied widely, the community-level shift was consistently earlier, independent of how we defined the core community. The weighted mean was consistent between the three community groups due to a few dominant taxa: Stephanodiscus niagarae (31 days earlier), Fragilaria crotonensis (13 days earlier), Cryptomonas sp. (53 days earlier), and Asterionella formosa (20 days earlier).

Dominant taxa were also an important driver of compositional shifts. The compositional component was largest $(60 \%)$ when all taxa were considered because Oscillatoria sp. comprised over $50 \%$ of the total biovolume from 1962 to 1967 and had a distinct summer peak. As Oscillatoria sp. decreased in dominance and eventually disappeared, the total phytoplankton peak shifted sharply toward spring. This is likely an extreme example, but even when the eutrophication-associated taxa were removed, compositional shifts explained $\sim 35 \%$ of the community shift. The most important taxa contributing to this compositional shift were earlyseason diatoms: Stephanodiscus niagarae, Aulacoseira subartica, and Stephanodiscus minutulus.

The difference in responses between community groupings with and without the eutrophication-associated taxa demonstrates the importance of nutrients as a driver of phytoplankton dynamics in Lake Washington (Edmondson et al. 2003). The largest effect of nutrients was on community composition at high nutrient levels due to shifts in the abundance of Oscillatoria sp., but nutrients may also affect phenology. Twelve taxa showed a relationship between phenology and total phosphorus levels; seven were positive and five were negative suggesting that phytoplankton response to nutrients is highly taxon specific (Elliott et al. 2006).

A common driver of phenology is changing climate, especially shifts in spring temperatures (Parmesan 2006). A substantial portion of the advancement of the phytoplankton peak occurred between 1970 and 1980 after Lake Washington had fully recovered from eutrophication, but during a time period of increased spring temperatures. Winder and Schindler (2004) examined the phenology of the diatom peak, the dominant phytoplankton group post eutrophication, and found a strong relationship with the onset of lake thermal stratification. We found that the phenological shifts of 10 phytoplankton taxa (including the dominant diatoms Aulacoseira subartica and Stephanodiscus niagarae) showed a positive relationship with the onset of stratification. Phytoplankton blooms likely track spring thermal stratification which controls the light and nutrient regimes necessary for germination and growth of overwintering diatoms (Reynolds 1984). The Pacific Decadal Oscillation (PDO) entered a warmer phase in the mid 1970s and the associated increased temperatures and earlier stratification line up closely with the timing of the phytoplankton peak (Winder and Schindler 2004).

The other important event that occurred in the mid 1970s was the appearance of Daphnia sp. in Lake Washington in 1976 (Edmondson and Litt 1982). Daphnia sp. is an important grazer that can alter phytoplankton community composition and phenology (Gaedke et al. 2010). At the community level, all three phytoplankton groupings showed a negative relationship with the abundance of grazers meaning that with an increase in grazers the day of peak phytoplankton biovolume shifted earlier. This could be due to phenological shifts (increased grazing caused the phytoplankton bloom to collapse earlier [Huber et al. 2008]) or compositional shifts (increased abundance of grazers favored early-season phytoplankton taxa). Daphnia sp. could affect phytoplankton composition directly through grazing or indirectly through the recycling of nutrients (Lehman 1980).

At the community level, it is difficult to estimate the importance of individual environmental drivers because not only were there taxa-specific phenological responses, but the mechanisms driving the shifts were also taxa specific. This is similar to what has been seen in other lakes (e.g., Thackeray et al. 2008). Shifts in phenology are often viewed as clear examples of climatic effects with a direct mechanistic link between temperature and phenology (Blenckner 2005), but there is a growing appreciation in both terrestrial and aquatic systems that phenological events are not primarily controlled by temperature (Korner and Basler 2010). In Lake Wash- 


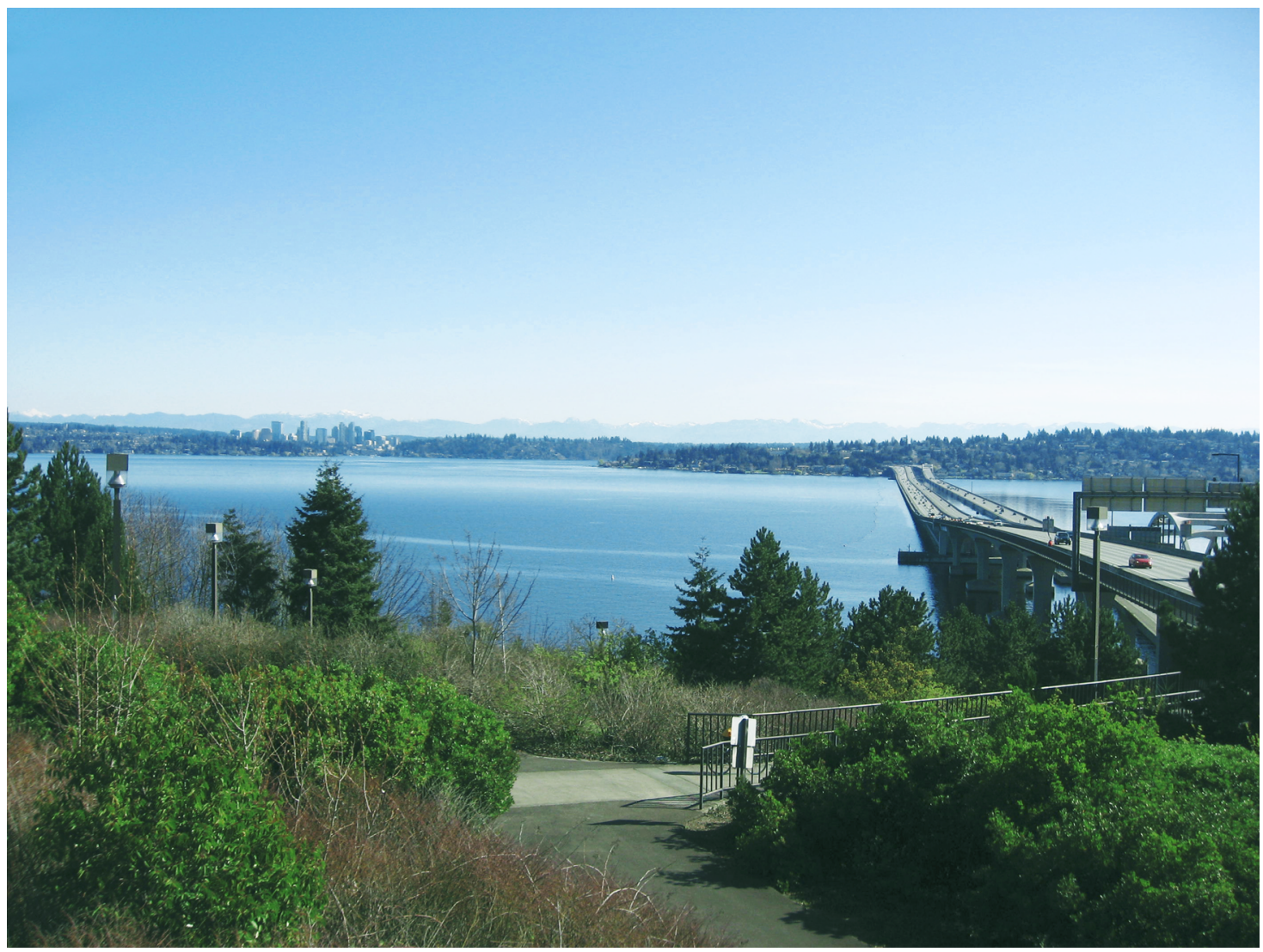

Plate 1. Lake Washington, Seattle, Washington, USA. The sampling site is located to the right of the floating bridge. Photo credit: A. W. Walters.

ington, there is strong evidence for climatic effects due to the relationship between the onset of stratification and the dominant diatoms, but the effect is only indirectly related to temperature. In addition, there is evidence to support a role of nutrients and grazing, especially with respect to compositional changes (Edmondson et al. 2003). For example, changes in silica loading to the lake may generate changes in the contributions of diatoms to the community; however, silica concentrations were not measured throughout the period of study we report on here so we have no means to assess its role in the patterns observed in Lake Washington.

The importance of compositional shifts highlights the fact that changes in community phenological patterns are produced by more than simply the sum of individual taxa phenological shifts. Recognition of the importance of shifts in community composition may explain some of the mismatches seen between species and community phenology. In Lake Washington, the community-level phenological shift was driven primarily by a few dominant taxa, either due to their phenological shifts, shifts in relative abundance, or a combination of both. To predict and understand phenological shifts in primary production for heterogeneous communities experiencing multiple stressors, both taxa-specific phe- nological shifts and shifts in community composition must be considered.

\section{ACKNOWLEDGMENTS}

We thank S. E. B. Abella for identifying phytoplankton, W. T. Edmondson for developing the long-term sampling program on Lake Washington, K. Gerow and R. AndersonSprecher for statistical advice, and the many people who have collected data, especially A. H. Litt. A. Strecker, S. Thackeray, and an anonymous reviewer provided valuable comments that improved the manuscript. A. W. Walters was supported by an NSF bioinformatics postdoctoral fellowship (DBI-1003038), and M. A. González Sagrario by a Fundación Antorchas postdoctoral fellowship. Long-term funding for the Lake Washington sampling program has been supported by the Andrew Mellon Foundation, the National Science Foundation, and the $\mathrm{H}$. Mason Keeler and Harriet Bullitt professorships. Any use of trade, firm, or product names is for descriptive purposes only and does not imply endorsement by the U.S. Government.

\section{Literature Cited}

Adrian, R., S. Wilhelm, and D. Gerten. 2006. Life-history traits of lake plankton species may govern their phenological response to climate warming. Global Change Biology 12: $652-661$.

Badeck, F. W., A. Bondeau, K. Bottcher, D. Doktor, W. Lucht, J. Schaber, and S. Sitch. 2004. Responses of spring phenology to climate change. New Phytologist 162:295-309.

Blenckner, T. 2005. A conceptual model of climate-related effects on lake ecosystems. Hydrobiologia 533:1-14. 
Cleland, E. E., N. R. Chiariello, S. R. Loarie, H. A. Mooney, and C. B. Field. 2006. Diverse responses of phenology to global changes in a grassland ecosystem. Proceedings of the National Academy of Sciences USA 103:13740-13744.

Cleland, E. E., I. Chuine, A. Menzel, H. A. Mooney, and M. D. Schwartz. 2007. Shifting plant phenology in response to global change. Trends in Ecology and Evolution 22:357-365

Edmondson, W. T., S. E. B. Abella, and J. T. Lehman. 2003. Phytoplankton in Lake Washington: long-term changes 1950-1999. Archiv fur Hydrobiologie Supplement 139:275326.

Edmondson, W. T., and A. H. Litt. 1982. Daphnia in Lake Washington. Limnology and Oceanography 27:272-293.

Edwards, M., and A. J. Richardson. 2004. Impact of climate change on marine pelagic phenology and trophic mismatch. Nature 430:881-884.

Elliott, J. A., I. D. Jones, and S. J. Thackeray. 2006. Testing the sensitivity of phytoplankton communities to changes in water temperature and nutrient load, in a temperate lake. Hydrobiologia 559:401-411.

Feuchtmayr, H., S. J. Thackeray, I. D. Jones, M. De Ville, J. Fletcher, B. James, and J. Kelly. 2012. Spring phytoplankton phenology - are patterns and drivers of change consistent among lakes in the same climatological region? Freshwater Biology 57:331-344.

Fisher, J. I., A. D. Richardson, and J. F. Mustard. 2007. Phenology model from surface meteorology does not capture satellite-based greenup estimations. Global Change Biology 13:707-721.

Gaedke, U., M. Ruhenstroth-Bauer, I. Wiegand, K. Tirok, N. Aberle, P. Breithaupt, K. Lengfellner, J. Wohlers, and U. Sommer. 2010. Biotic interactions may overrule direct climate effects on spring phytoplankton dynamics. Global Change Biology 16:1122-1136.

Guinder, V. A., C. A. Popovich, J. C. Molinero, and G. M. E. Perillo. 2010. Long-term changes in phytoplankton phenology and community structure in the Bahia Blanca Estuary, Argentina. Marine Biology 157:2703-2716.

Huber, V., R. Adrian, and D. Gerten. 2008. Phytoplankton response to climate warming modified by trophic state. Limnology and Oceanography 53:1-13.

Kahru, M., V. Brotas, M. Manzano-Sarabia, and B. G. Mitchell. 2011. Are phytoplankton blooms occurring earlier in the Arctic? Global Change Biology 17:1733-1739.
Korner, C., and D. Basler. 2010. Phenology under global warming. Science 327:1461-1462.

Lehman, J. T. 1980. Release and cycling of nutrients between planktonic algae and herbivores. Limnology and Oceanography 25:620-632.

Meis, S., S. J. Thackeray, and I. D. Jones. 2009. Effects of recent climate change on phytoplankton phenology in a temperate lake. Freshwater Biology 54:1888-1898.

Myneni, R. B., C. D. Keeling, C. J. Tucker, G. Asrar, and R. R. Nemani. 1997. Increased plant growth in the northern high latitudes from 1981 to 1991. Nature 386:698-702.

Parmesan, C. 2006. Ecological and evolutionary responses to recent climate change. Annual Review of Ecology Evolution and Systematics 37:637-669.

Post, E., and C. Pedersen. 2008. Opposing plant community responses to warming with and without herbivores. Proceedings of the National Academy of Sciences USA 105:1235312358

R Development Core Team. 2011. R: a language and environment for statistical computing. $\mathrm{R}$ Foundation for Statistical Computing, Vienna, Austria. www.r-project.org

Reynolds, C. S. 1984. The ecology of freshwater phytoplankton. Cambridge University Press, Cambridge, UK.

Schwartz, M. D., B. C. Reed, and M. A. White. 2002. Assessing satellite-derived start-of-season measures in the conterminous USA. International Journal of Climatology 22:1793-1805.

Steltzer, H., and E. Post. 2009. Seasons and life cycles. Science 324:886-887.

Thackeray, S. J., I. D. Jones, and S. C. Maberly. 2008. Longterm change in the phenology of spring phytoplankton: species-specific responses to nutrient enrichment and climatic change. Journal of Ecology 96:523-535.

Vasseur, D. A., and U. Gaedke. 2007. Spectral analysis unmasks synchronous and compensatory dynamics in plankton communities. Ecology 88:2058-2071.

Winder, M., and D. E. Schindler. 2004. Climatic effects on the phenology of lake processes. Global Change Biology 10: $1844-1856$.

Wood, S. N. 2006. Generalized additive models: an introduction with R. Chapman and Hall/CRC, Boca Raton, Florida, USA.

Zuur, A. F., E. N. Ieno, N. J. Walker, A. A. Saveliev, and G. M. Smith. 2009. Mixed effects models and extensions in ecology with R. Springer, New York, New York, USA.

\section{Supplemental Material}

Appendix A

Characteristics of all phytoplankton taxa considered in the analysis (Ecological Archives E094-204-A1).

\section{Appendix B}

Results for analysis considering alternative grazing metrics (Ecological Archives E094-204-A2).

\section{Appendix C}

Histograms showing the coefficient distribution for the taxa-level multiple linear regressions (Ecological Archives E094-204-A3). 